\title{
PRESENÇAS DA CULTURA REGIONAL NOS TELEJORNAIS ESTADUAIS
}

\section{ATTENDANCE OF REGIONAL CULTURE IN THE STATE TV NEWS}

\author{
Flavi Ferreira Lisboa Filho* \\ Fernanda do Amaral Ferrari ${ }^{* *}$ \\ Helen Piegas Barcelos ${ }^{* * *}$
}

\begin{abstract}
RESUMO
Este estudo centra-se em identificar as estratégias de comunicação que os telejornais do Rio Grande do Sul utilizam para representar a gauchidade nos programas. Trata-se de uma pesquisa qualitativa que analisa três edições de cada telejornal das emissoras RBS TV, Band e Record, durante as comemorações da Semana Farroupilha. Verificou-se que a gauchidade é marcada pela interação dos apresentadores com o telespectador e pelo incentivo ao consumo de bens simbólicos mais próximos dos tradicionalistas. De modo geral, a mídia, em específico os telejornais, dão continuidade às manifestações culturais e à preservação da identidade gáucha, da mesma forma, que as atualizam.
\end{abstract}

Palavras-chave: Cultura regional. Gauchidade. Telejornal.

\begin{abstract}
This study focuses on identifying the communication strategies used by television newscasts in Rio Grande do Sul to represent the "gauchidade" in newscasts. This qualitative study examines three editions of each television news broadcasters: RBS TV, Band and Record during the celebrations of "Farroupilha Week". It was observed that the "gauchidade" is marked by the interaction of the presenters with the viewer and by encouraging the consumption of symbolic goods related to the traditionalists. The media in general, and more specifically the television newscasts, give continuity to the cultural manifestations and emphasize the preservation of their culture identity, as well as update them.
\end{abstract}

Keywords: Regional culture. Gauchidade. Television News

\section{Considerações Iniciais}

A televisão se constitui em um veículo de comunicação que aponta diferentes registros midiáticos, cuja programação é composta por diversos formatos e gêneros. A trajetória da televisão mostra que ela é um veículo de comunicação de ampla cobertura e penetração entre todas as classes sociais da população. Principal fonte de informações e entretenimento para muitos, é fundamental na propagação de conhecimentos, na difusão cultural e no processo de construção ou legitimação de identidades/ identificações.

\footnotetext{
* Doutor em Ciências da Comunicação, área de processos midiáticos, pelo Programa de Pós-Graduação em Ciências da Comunicação da Universidade do Vale do Rio dos Sinos. Professor Adjunto do Departamento de Ciências da Comunicação da Universidade Federal de Santa Maria. Pesquisador do Grupo Comunicação, Identidade e Fronteira da UFSM.

*** Acadêmica do Curso de Comunicação Social da Universidade Federal do Pampa. Bolsista PIBIC-CNPq.

*** Bacharel em Comunicação Social: hab. Publicidade e Propaganda e graduanda pela Universidade Federal do Pampa.
} 
Para este trabalho, optou-se pelos telejornais em função da sua presença diária na transmissão de notícias, crônicas e comentários. Delimitou-se ao segmento regional por enfatizarem reportagens locais e por estarem marcados de alguma forma pela gauchidade ${ }^{1}$.

Nosso objetivo centra-se em analisar as significações construídas pela mídia nos telejornais do estado, por meio de atores discursivos e sociais, ambientação, usos de linguagem e pelas marcas que representam o regionalismo inserido no discurso televisual. Assim, é possível dar os primeiros passos no sentido de perceber os processos identitários construídos pelos telejornais na representação do gaúcho. Para tanto, foram selecionados os telejornais das três emissoras presentes no Rio Grande do Sul (Bandeirantes, RBS TV e Rede Record), que produzem notícias locais/regionais.

\section{A Televisão e o Telejornal: uma breve aproximação}

Para pensar em televisão e identidade regional devemos levar em conta o grande acesso às mais variadas mídias. Atualmente, nos encontramos em um ambiente digital, tendo experiência e contato com a tecnologia. Apesar do crescimento constante de alguns meios, isso não quer dizer que a televisão deixa de ser um dos meios mais significativos para a população em geral, mas que devemos levar em conta que o telespectador busca informação e tem conexões com ambientes e conteúdos diversos. No caso da televisão, ela pode ser acessada de aparelho fixo, celular, computador, em qualquer hora e lugar; à medida que a tecnologia ganha força, a exibição televisual se ramifica e isso tende a ampliar sua força de penetração.

O cidadão busca os meios para informação, entretenimento, curiosidades, mas também sente a necessidade de sua localização, espaço e tempo, e é aí que se determinam os suportes em que se oferece a programação. A televisão regional tenta fazer a relação do meio em que se vive, ou seja, do local onde ela está inserida e dos elementos que caracterizam a região em que se tem a cobertura.

\footnotetext{
Lisboa Filho (2009. p. 20): "o termo gauchidade busca trazer a idéia de fenômeno, abrindo possibilidades para a investigação de qualidades, comportamentos, valores, maneiras de agir, sendo mais abrangente, permitindo a consideração de múltiplas formas discursivas de representação do que é ser gaúcho".
}

A televisão como mídia, muitas vezes, assume o papel de preservação da história, atualizando costumes. Ela se mostra próxima do público, de forma que ele se identifica com essa forma midiática criando uma dependência de ambas as partes. Através do discurso serializado, da repetição das imagens, a mídia chama a atenção do público e o ganha pela insistência e pela versatilidade.

$\mathrm{Na}$ televisão, os telejornais procuram apresentadores e formatos diversificados. "Sem dúvida, em qualquer formato de programa jornalístico na televisão, o apresentador é a figura central, aquele que representa a 'cara' do programa, e mais importante, que constrói a ligação entre o telespectador e os outros jornalistas que fazem o programa". (GOMES, 2006, p. 112).

Essa ligação que se constrói entre telespectador e apresentador é o modo de endereçamento, ou seja, a forma pela qual o apresentador se comunica com quem o programa procura atingir. Para uma maior aceitação do telespectador, muitos telejornais procuram fugir do formato padrão por meio de formatos que chamem a atenção do público específico, como os programas voltados para o entretenimento, acontecimentos policiais e outros.

Um telejornal sempre apresenta definições dos seus participantes, dos objetivos e dos modos de comunicar, explicitamente ("você, amigo da rede globo", "para o amigo que está chegando em casa agora", "esta é a principal notícia do dia", "Agilidade, dinamismo e credibilidade é o que queremos trazer para você", "você é meu parceiro, nós vamos juntos onde a notícia está") - ou implicitamente - através das escolhas técnicas, do cenário, da postura do apresentador. (GOMES, 2006, p.115).

As falas, tecnologias de imagem e som e a exibição de como produzem as notícias também fazem parte da credibilidade e veracidade que a emissora/programa deseja mostrar.

A exibição das redações como pano de fundo para a bancada dos apresentadores na maior parte dos telejornais atuais é apenas uma dessas estratégias de construção de credibilidade e, ao mesmo tempo, de aproximação do telespectador, que se torna, assim, cúmplice do trabalho de produção jornalística. Mas ainda as transmissões ao vivo são o melhor exemplo do modo como os programas 
buscam o reconhecimento da autenticidade de sua cobertura por parte da audiência. (GOMES, 2006, p. 116).

A utilização de telespectadores para a construção da notícia é observada em dois tipos de fontes, basicamente: a autoridade e o cidadão comum. $\mathrm{O}$ primeiro serve para transferir validade à notícia e o segundo pode ser o que foi afetado pela notícia, quando ele é a notícia ou quando ele simplesmente dá sua opinião.

\section{Quanto à Identidade Cultural}

O tema "identidade" está ligado e associado a grupos que ocupam o mesmo espaço ou pertencimento, como questões étnicas, nacionais, lingüísticas, religiosas, etc. A identidade se define pelas atividades, histórias e traços de uma personalidade. São características de um indivíduo, ou de um grupo de pessoas que possuem as mesmas oposições de comportamento, compartilham dos mesmos valores, regras morais. De certa forma, a identidade consiste em caracteres que nos diferenciam uns dos outros, marcados pela diferença. Para Hall (2006 p.106), "identificação", na linguagem do senso comum, é construída a partir do reconhecimento de alguma origem comum, ou de características partilhadas com outros grupos ou pessoas, ou ainda a partir de um mesmo ideal.

A partir das mudanças estruturais que ocorrem na sociedade moderna no final do século $\mathrm{XX}$, tem origem uma fragmentação nos termos como classe, gênero, entre outros. $\mathrm{O}$ fato é que antes a identidade era calcada em um sujeito unificado, que fornecia concepções mais sólidas acerca de sua constituição. Para Hall (2006, p. 10), "o sujeito nascia e com ele se desenvolvia, ainda que permanecendo essencialmente o mesmo, contínuo ou 'idêntico' a ele ao longo da existência do indivíduo".

Com a transformação e a complexidade do mundo moderno, a identidade pode ser constituída a partir da influência mútua do "eu" com a sociedade. O sujeito tem uma essência do "eu real", e ao mesmo tempo lhe são proporcionados valores ou significados culturais de um "mundo externo". Consequentemente, a identidade já não é unificada e sim fragmentada; ou melhor, são múltiplas essas alterações do exterior que farão parte de nós, compondo várias identidades.
Esse processo produz o sujeito pós-moderno, conceptualizado como não tendo uma identidade fixa, essencial ou permanente. A identidade é formada e transformada continuamente em relação às formas pelas quais somos representados ou interpelados no sistema cultural que nos rodeia. (HALL, 2006, p.13).

O movimento da interconexão entre as pessoas ocorre em qualquer lugar e a qualquer momento, e incide em uma transferência de informações que levam a novos conteúdos, valores, sensibilidades e múltiplos caminhos. Com os avanços e conhecimentos em diversas áreas, somos submergidos por diferentes grupos sociais e, consequentemente, produzirmos uma variedade de sujeitos, ou seja, de identidades. Um exemplo é o nosso dia a dia, o cenário onde somos posicionados a várias representações, dependendo das situações em que nos encontramos. Em alguns grupos de identidades diferentes, mas com determinados princípios em comum, que não se modificam, as pessoas deixam que suas identidades diferentes possam ser trabalhadas juntas.

Hall (2006, p.11) diz que "o sujeito tem um núcleo ou essência interior que é o 'eu real', mas este é formado e modificado num diálogo contínuo com mundos culturais 'exteriores' e as identidades que esses mundos oferecem”. Nesse entendimento, os valores e significações vão se tornando parte de nós. O termo identidade está em constante desenvolvimento, pois a relação social contemporânea encontra-se em constante mudança.

Pode-se dizer que a questão da identidade pós-moderna é calcada na possibilidade de mudança constante e que, a partir desses movimentos, observa-se o surgimento de novas identidades.

Se examinarmos algumas questões contemporâneas de identidade, podemos observar que ela existe de diferentes níveis, em um nível "global", por exemplo, as identidades étnicas ou nacionais, e em um nível "local", como relações pessoais e política sexual. Para entender identidade, é necessário compreender suas representações, e analisar sua relação entre cultura e significado. (WOODWARD, 2006, p.16).

Nesse sentido, a identidade gaúcha provém de acontecimentos históricos e culturais do estado. Essa cultura é marcada por hábitos e costumes como a lida campeira, o gosto pela criação de gado 
e cavalos, o hábito de tomar o chimarrão -, além da culinária, com o carreteiro e o churrasco, festivais de música nativista, rodeios e concursos de danças. Tudo isso faz parte de uma cultura gaúcha em que a identidade se caracteriza pela preservação dos costumes, da tradição e do folclore.

Segundo Oliven (apud Lisboa Filho, 2009, p. 173), a construção social da identidade sul-rio-grandense provém de elementos recuperados a partir de uma visão gloriosa do passado, associando o gaúcho à força, à belicosidade e à liberdade. Todas essas características acabam contribuindo para a conformação de uma construção cultural da identidade gaúcha tradicional, mesmo que não façam mais parte da vida cotidiana desse povo.

A preservação e a atualização da cultura regional do estado do Rio Grande do Sul são feitas, em grande parte, pela mídia. Cabe ressaltar que essa atualização é intensificada no mês de setembro, quando se comemora a Semana Farroupilha e o Dia do Gaúcho. Hobsbawm e Ranger (apud Lisboa Filho, 2009, p. 176) contribuem para o entendimento da dualística "preservação versus atualização", ao dizer que "o culto à tradição não se opõe à modernidade. Ele se reproduz nela e, graças a ela, se mantém".

No senso comum, a regulamentação da identidade sugere uma "escolha" de imagem, comportamento, grupo, que é direcionada pelos veículos de comunicação e que pode nos fazer "perder" no ambiente pós-moderno e nos localizar na arte da ficção.

\section{Metodologia}

O desenvolvimento do trabalho deu-se através de uma pesquisa qualitativa voltada para a análise de textos televisivos que associam som, imagem e movimento, na qual foram feitos os levantamentos das principais estratégias empregadas na produção dos telejornais das emissoras Band, Record e RBS TV no Rio Grande do Sul.

A partir do levantamento, foram especificados os telejornais de maior relevância e destaque para a pesquisa, de acordo com a proposta apresentada. Fez-se o uso da captação de três edições de cada programa, com a exibição de segunda a sábado. Os programas foram gravados durante o período da Semana Farroupilha, de treze a vinte de setembro, por serem esses os dias em que a cultura gaúcha regional está mais insuflada na mídia. Foram decupados os telejornais Tele Domingo, RS Acontece, Band Cidade, Rio Grande no Ar, Jornal do Almoço, Bom Dia Rio Grande, RBS Notícias e Rio Grande Record.

Há de se considerar, também, que a análise televisiva não compreende apenas o procedimento metodológico usado no trabalho ora apresentado. Percebemos que o objeto dessa investigação pode ser estudado por uma das perspectivas da pesquisa exploratória, que parte de um esforço de aproximação para angariar dados e construir estratégias metodológicas próprias, capazes de reunir diferentes técnicas e procedimentos da pesquisa qualitativa com conceituações e instrumentos dos estudos culturais e da análise textual. (CASETTI e CHIO, 1999).

\section{Resultados}

Os resultados estão dispostos por emissoras. Primeiro apresenta-se a RBS TV com seus telejornais, após a Band e a Record. No final de cada subseção faz-se uma conclusão parcial, com o intuito de, ao final, verificarmos se existe alguma diferença na construção dos telejornais entre as emissoras.

\section{RBS TV}

\section{Bom Dia Rio Grande}

Exibido às seis e meia da manhã, de segunda a sexta, o programa possui quatro blocos e três intervalos, com o total de quarenta e cinco minutos de duração. Os apresentadores variam conforme o dia, exceto Luiza Sancheta, que faz a previsão do tempo; contudo, eles estão sempre em duplas e posicionados atrás da bancada. A vinheta de abertura (Figura 1) é feita com a formação do mapa do RS com listras azuis, que remete a uma lavoura; o fundo amarelo causa uma impressão de sol, iluminando o canto superior direito, referindo-se ao amanhecer no estado. A locomoção da câmera e a disposição das listras amarelas dão a impressão de um cilindro que representa o movimento de rotação da terra e as notícias que acontecem ao redor e dentro do estado. 
Figura 1 - Vinheta de Abertura do Jornal Bom Dia Rio Grande

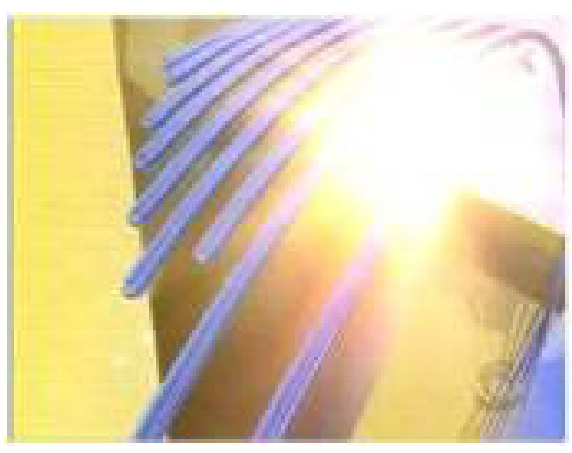

O cenário é composto por uma bancada, onde ficam sentados os apresentadores, e ao fundo são mostradas imagens que representam o RS, como a catedral metropolitana (Igreja Mãe de Deus), o mercado público de Porto Alegre, o palácio Piratini e a estátua do Laçador, sendo esta última uma alusão direta à representação do gaúcho. Fica clara a importância dessas imagens, no momento em que o monumento é comparado aos "poderes" da Igreja e do estado.

O programa inicia e termina com um oferecimento do Sicredi e faz referências aos jornais do grupo RBS ao longo do programa - Diário Gaúcho, Diário de Santa Maria, Pioneiro, Jornal de SC, Diário Catarinense, A notícia e A Hora.

Durante a semana, notícias como tempo, saúde, política e cultura foram citadas, porém nenhuma foi tão presente quanto a Semana Farroupilha. Algumas falas foram de grande representatividade no que se refere à gauchidade. Ao citarem o chimarrão e o churrasco como símbolos de hospitalidade do gaúcho e acrescentarem que a água está sempre quente para receber os visitantes, os apresentadores chamam a todos para uma visita ao Estado e à cultura regional.

Entretanto, ao mostrar um "concurso de chula", com a participação do Guri de Uruguaiana, de um campeão pan-americano de ginástica e de Liturgo, um gaúcho emo, percebe-se certa exclusão. Ao longo do programa o ginasta e o emo não tomam a palavra; ela é utilizada apenas pelo Guri de Uruguaiana, que fala sobre a masculinidade do gaúcho. Nota-se, dessa forma, que a inclusão de outros é apenas para produzir um efeito de democracia. Há uma nítida prevalência da ideia do "gaúcho macho" representado pelo Guri de Uruguaiana, em detrimento dos outros convidados.
Outro ponto relevante é a forma que os apresentadores atualizaram a gauchidade, por meio de uma roda de chimarrão virtual. Eles falaram que a utilização das vestimentas ditadas pelo MTG já não é mais a única forma de representar seu apreço pela cultura gaúcha. Também mostraram jovens que falam da tentativa de unir o velho tradicionalismo com o contemporâneo, além de apresentarem pessoas que, apesar de vestimentas modernas e de não estarem no RS, se mostram gaúchos pelo hábito de tomar chimarrão.

\section{Jornal do Almoço}

Exibido ao meio dia, de segunda-feira a sábado, o programa possui quatro blocos e três intervalos, totalizando cerca de quarenta e cinco minutos. Há um bloco local/regional, produzido pelas emissoras-rede da RBS.

A vinheta de abertura (Figura 2) é feita com um fundo azul e as letras J e A também em azul, porém em um ângulo diagonal e com percepção transparente. $\mathrm{O}$ fundo em azul remete ao céu, uma ideia de cobertura em todo o estado. 
Figura 2 - Vinheta de Abertura do Jornal do Almoço

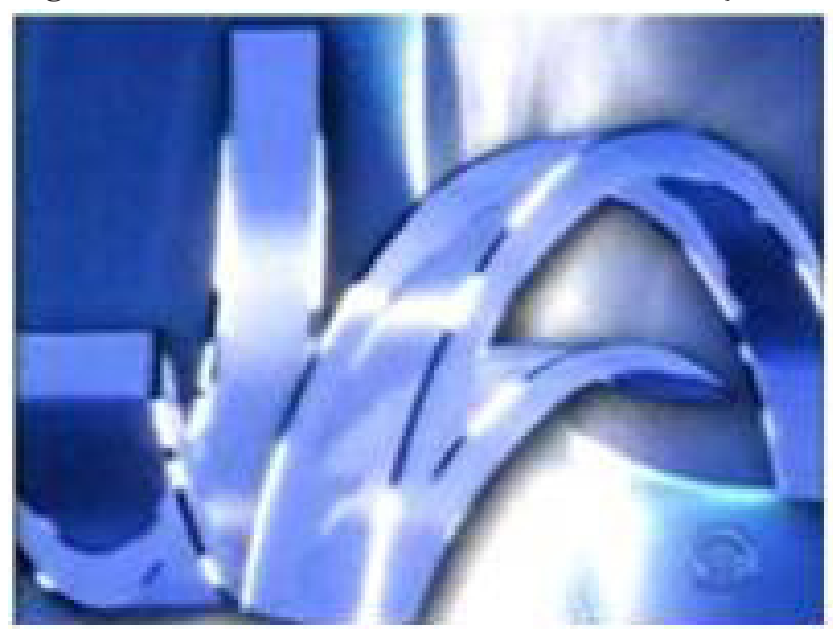

O cenário é constituído com as mesmas imagens vistas no plano de fundo do "Bom Dia Rio Grande". No geral, o programa tem o oferecimento da Pompéia e não possui merchandising percebível.

Em relação à Semana Farroupilha, a questão das tradições foi marcada pela exibição de danças folclóricas e jogos apresentados por crianças. Além disso, houve falas de que essas práticas reforçam a importância do tradicionalismo na educação das crianças, "porque se não estão dentro do tradicionalismo, elas estão nas ruas". Assim, o programa passa a ideia de que as crianças, por praticarem essas atividades ritualísticas, são imbuídas de uma boa educação e uma boa índole, como se fosse possível criar um escudo de proteção contra os males da sociedade. De certa forma, faz uma separação entre o "bem" e o "mal". Obviamente, o bem está relacionado ao culto da tradição e certa militância no MTG.

Para mostrar como a Semana Farroupilha é marcante no estado, o apresentador pede a participação do telespectador com o envio de vídeos que mostrem sua "paixão pelo Rio Grande". Na ideia de unir os gaúchos, o programa destaca que as comemorações tiveram até uma reprodução inusitada do clássico do futebol gaúcho (Grêmio x Internacional) em Brasília, com os jogadores (grupo de amigos) de bombacha. Dessa forma, une dois símbolos gaúchos, dando a entender que dentro da tradição gaúcha a rivalidade não tem vez.

Outra pauta foi a chegada da chama crioula ao palácio Piratini, levada por cavalarianos. O programa mostrou a governadora do estado recepcionando-os, fato esse que leva o telespectador a de-

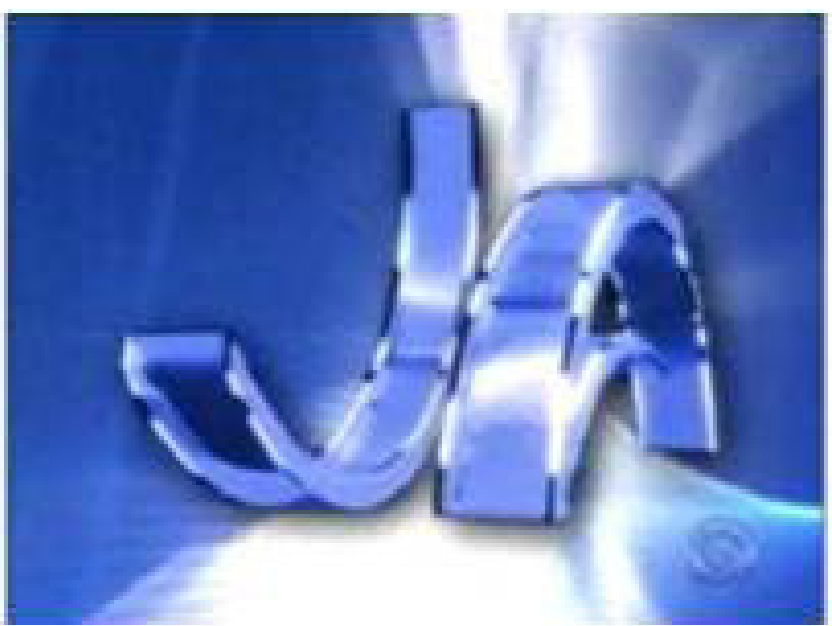

duzir a importância da Semana Farroupilha, pois a representante do poder político do estado dá início às comemorações e delas participa.

\section{RBS Notícias}

Exibido às $18 \mathrm{~h} 50 \mathrm{~min}$, com o oferecimento do Banrisul, o programa tem duração de quinze minutos, constituído de três blocos com dois intervalos de dois minutos. Os apresentadores em duplas, geralmente Eloi Zorzetto e Cristina Vieira, estão sentados atrás de uma bancada, ao lado de uma televisão.

A vinheta de abertura (Figura 3) aparece com o surgimento de letra por letra montando o RBSN (RBS Notícias) dentro de um mapa do RS e com listas passando, conotando a velocidade da recepção da notícia. 
Figura 3 - Vinheta de Abertura do RBS Notícias
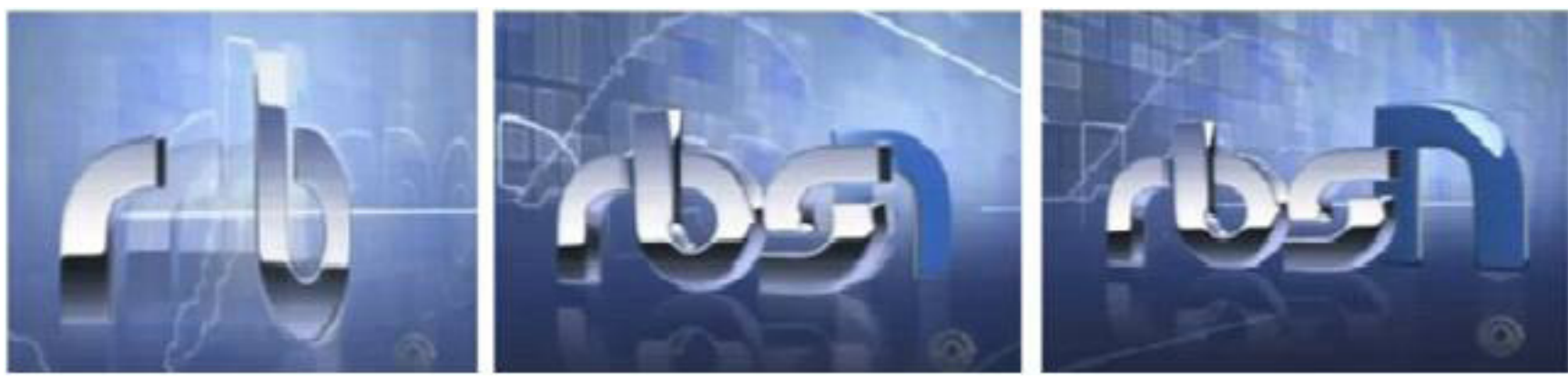

Quanto à Semana Farroupilha, a preferência se deu para o consumo dos bens simbólicos, mostrando lojas com funcionários caracterizados em trajes típicos e pessoas consumindo. $\mathrm{Na}$ fala "Independente da indumentária, essa data é a mais esperada por quem se dedica a esse público e não deixa morrer a tradição" fica nítido o desejo de consumo. Essa é uma das principais formas de se identificar tal desejo com a cultura gaúcha, pois utilizando e consumindo os bens simbólicos, deduz-se que o sujeito pode se tornar "mais" gaúcho. Outro ponto de destaque é a utilização de palavras como "apetrechos" e "tchê", que marcam e lembram o peão e a lida no campo.

\section{Tele Domingo}

Exibido nos domingos à noite, o programa possui três blocos e dois intervalos que totalizam quarenta minutos. Os apresentadores são sempre os mesmos, Regina Lima e Túlio Lilmam, que se encontram em pé, em um cenário virtual.

Com o oferecimento das Bombas Müller e Ótica Requinte, patrocinadores locais, a vinheta de abertura (Figura 4) é feita com a palavra "Tele Domingo" em amarelo, passando como uma espécie de carro flutuante no meio de prédios e ruas de Porto Alegre, dando ares de modernidade.

Figura 4 - Vinheta de Abertura do Tele Domingo
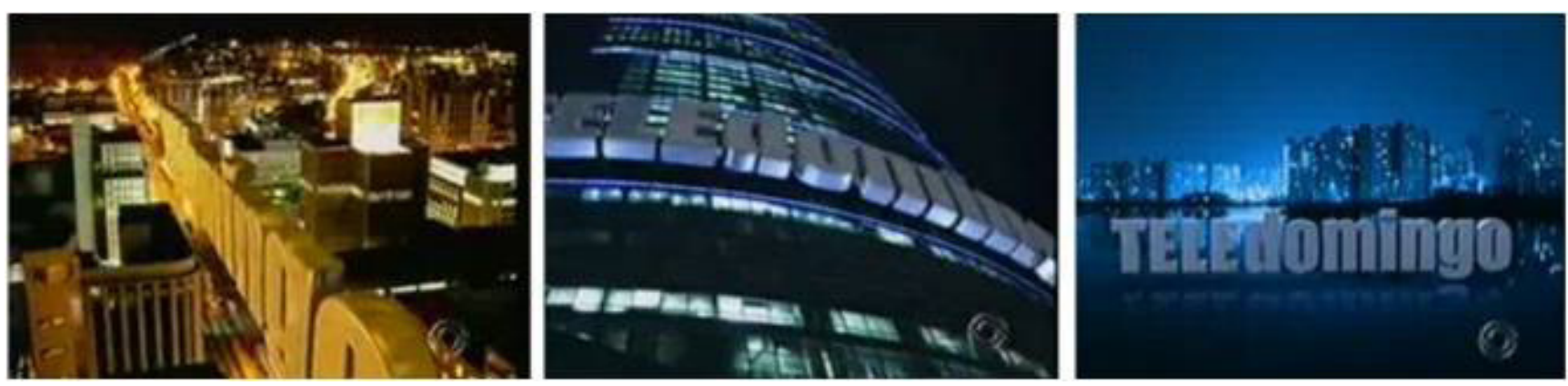

O telejornal faz um resumo semanal das matérias mais significativas, segundo seu editor-chefe. A Semana Farroupilha fica marcada pela presença de um homem pichado dizendo: "o Tele Domingo no ar é campeão de sintonia”. De certa forma, mostra que o gaúcho dá credibilidade ao programa, ou seja, mostra o gaúcho como depoimento de confiança.

Após, os apresentadores declamam uma das letras de música mais tradicionais do Estado, "É disso que o velho gosta", do Gaúcho da Fronteira, representando a intensidade e a proximidade desses símbolos culturais com o cotidiano.
Na previsão do tempo, a chuva foi relacionada com a tradição, ao enunciarem que nem o mau tempo (clima) do mês de setembro atrapalha as comemorações da Semana, porque o sentimento farroupilha é mais forte. Ainda relacionado ao clima, os acampados dizem que não sentem cansaço ou sono, demonstrando assim certa aderência com o tema deste ano, "Farroupilhas e suas Façanhas", ou seja, mostram que são gaúchos guerreiros, que enfrentam qualquer mau tempo ou condições adversas. Esse fato é reforçado, ao dizerem: "Quero pedir ao capataz do universo, que mesmo em simples 
gesto peça ao patrão supremo, que olhe aqui para baixo, para os campos e as coxilhas, e não deixe morrer a alma dos farroupilhas".

Outro ponto a ser destacado é o efeito de familiaridade, pois a partir de um sentimento transmitido de avô para neto faz-se com que a tradição não se perca e esteja sempre presente.

Figura 5 - Imagens dos Apresentadores

\section{BAND}

\section{Band Cidade}

Exibido às 18h50min, o programa possui quatro blocos e três intervalos que totalizam trinta minutos no ar, com os mesmos apresentadores, Lúcia Mattos e Felipe Vieira (Figura 5), sentados atrás de uma bancada que fica em frente de uma parede onde se lê "Band Cidade".

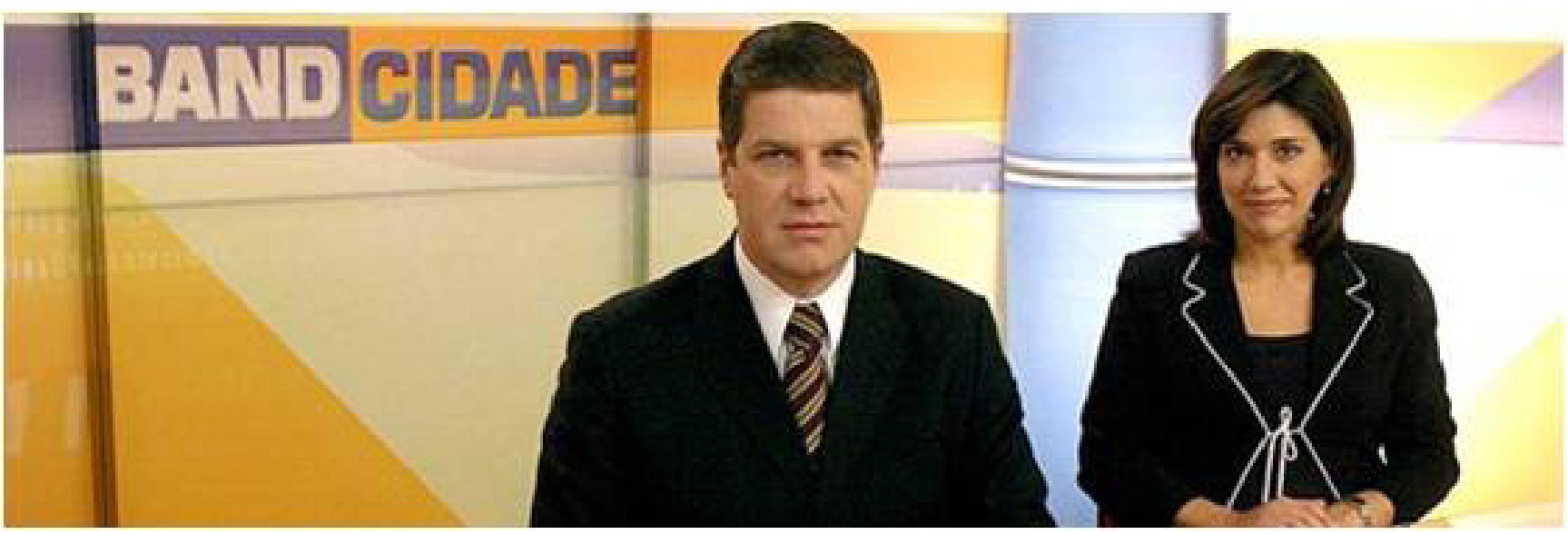

A vinheta de abertura (Figura 6) é feita com um movimento rápido em quadrados laranja, um ao lado do outro, passando a ideia de quarteirões de uma cidade. Após, surge uma lista dividida ao meio por cores (amarelo e azul), em que se lê Band Cidade.

Figura 6 - Vinheta de Abertura do Band Cidade
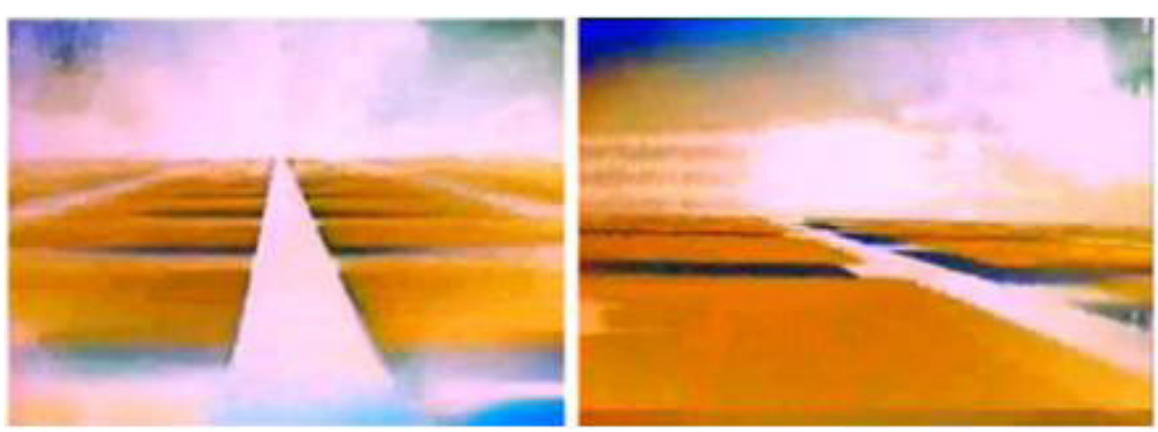

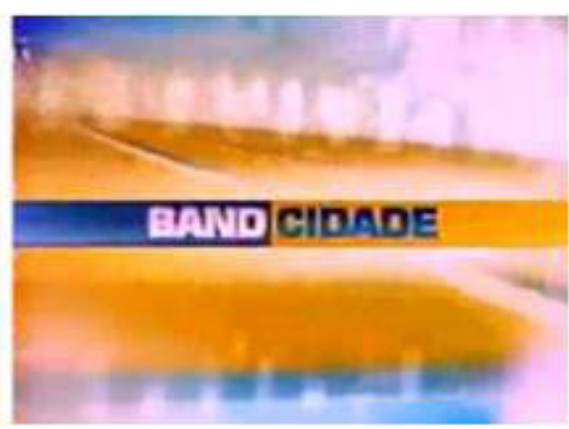

Na Semana Farroupilha a busca pelo resgate da história foi marcada através de matérias que mostraram um museu montado em um dos piquetes, com o propósito de difundir a cultura gaúcha tradicionalista.

Em todos os momentos o programa procurou mostrar pessoas animadas tomando chimarrão e, ao mesmo tempo, unindo pessoas de todas as partes, pelo uso da internet, especialmente ao dizerem: "é muito diferente, mas é muito macanudo".As palavras "é muito diferente" podem ser interpretadas como sendo a internet diferente por ser nova e por ser incomum seu uso para preservação da tradição, e "macanudo" por ser algo que pode contribuir com a tradição.

Embora a maior parte da população do estado se constitua como urbana, outra relação feita foi a do cavalo como o melhor amigo do homem, em função de estar sempre presente nas lidas de campo e de se tornar um amigo que entende e ajuda o peão durante o trabalho. 


\section{RS Acontece}

Exibido às sete e trinta da manhã, com oferecimento da Kia San Motors e do Banrisul, o programa possui três blocos realizados em meia hora. Os apresentadores são Fernanda Farias e Sérgio Stook, contudo ele aparece sozinho em alguns programas. Ambos se apresentam em pé, ao lado de uma televisão.
A vinheta de abertura (Figura 7) é feita com o surgimento de um quadro laranja, no centro do qual se lê RS Acontece. O movimento do quadro laranja mostra, simbolicamente, a velocidade das reportagens e a dinamicidade do programa. $\mathrm{O}$ fundo que vai do amarelo (parte inferior) ao azul se refere ao amanhecer, que, junto com os "holofotes" brancos, dá ênfase ao nome do jornal.

Figura 7 - Vinheta de Abertura do RS Acontece
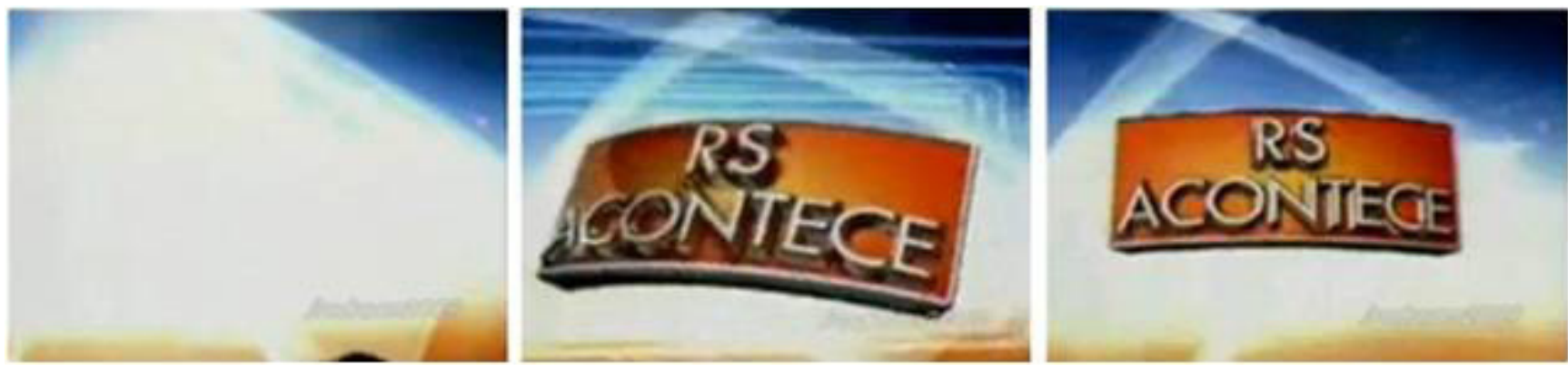

Algumas reportagens se repetem do Band Cidade para o RS Acontece, mas ainda se podem analisar questões interessantes. Afinal, em um dos programas a reportagem destinada à Semana Farroupilha foi de onze minutos, isto é, todo o tempo de duração do último bloco.

Uma fala é feita em alusão ao clima ruim e ao tempo bom, associando as condições do acampamento farroupilha, onde dizem que, apesar da lama dentro dos piquetes, havia muita comida típica, chimarrão e dança, mostrando que essas tradições são mais fortes. Em um dos dias, o programa ressaltou a importância de resgatar a cultura gaúcha através de uma bibliopark para crianças. Outro elemento citado foi o Restaurante Crioulo, com shows de grupos nativistas que acontecem durante a noite.

Em relação à música, os apresentadores mostraram o bugio, cantado pelo grupo Gaudérios do CTG Chimangos. Eles disseram que a música se chama assim em função do ronco do animal. Os músicos utilizaram instrumentos como gaita, violão e borongue. A demonstração do som e da imagem desses instrumentos faz com que se resgate um pouco da história gaúcha, afinal trata-se de uma música oriunda dos festivais nativistas.

\section{RECORD}

\section{Rio Grande no Ar}

O programa possui dois blocos que totalizam uma hora e quinze minutos de programa. Os apresentadores, Kelen Caldas e André Haar, apresentam-se sentados atrás de uma bancada posicionada em frente à redação do jornal.

A vinheta de abertura (Figura 8) é formada pelo surgimento de quadrados azuis e sua montagem em outro maior, surgindo um quadrado único no qual se lê "Rio Grande"; as palavras "no ar" estão escritas em um quadrado vermelho mais abaixo. Os pequenos quadrados em azul se referem à variedade de notícias. Como a união desses elementos forma o mapa do estado, deduz-se que todos os acontecimentos estão no programa "Rio Grande no Ar", que aparece escrito ao fim. 
Figura 8 - Vinheta de Abertura do Rio Grande no Ar
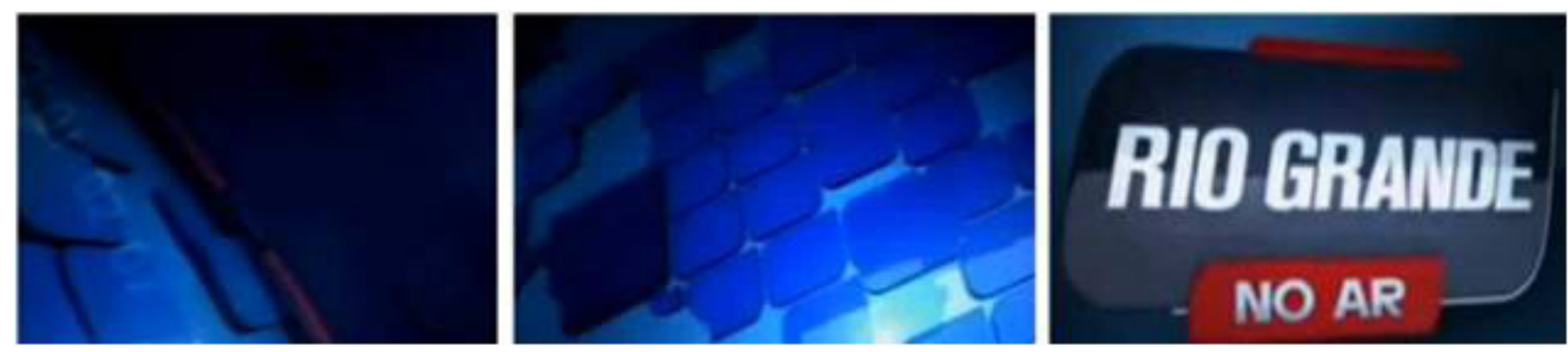

Os patrocinadores são a Caixa Econômica Federal, SESCRS, Kia Sun Motors e Ótica São José. Além da autorreferenciação, falando que a Record participa de um projeto de arrecadação para a sociedade Pestalozzi, que ajuda crianças especiais, outra é sobre o que os apresentadores chamam de "o maior lançamento de informações pela Internet", o R7, um portal de notícias da Record. Uma última é o merchandising sobre o jornal Correio do Povo, propriedade da emissora.

Com notícias sobre tempo, saúde, política e ação criminal, as matérias de cada jornal se resumem a uma ou duas reportagens que falam sobre o acampamento farroupilha. Dizem que esse acampamento virou uma "pequena cidade gaudéria", onde pode ser encontrado tudo para não se deixar os costumes. Nota-se, assim, uma atualização da gauchidade, por esses telejornais exibirem os espaços comerciais utilizados pelos açougues e mercados para o consumo de bens simbólicos no parque.

Outro ponto abordado foi "a maior roda de chimarrão do mundo". Dizem os apresentadores que "o gaúcho tem orgulho de suas raízes e tradições ninguém dúvida, mas tem gente que quer compartilhar esses hábitos com o mundo todo", e defendem essa ideia. Dessa forma, nota-se o apelo para que se espalhe a identidade do estado por todos os cantos do mundo, de forma que todo mundo aprecie as tradições e os hábitos gaúchos e com eles se identifique. Isso pode ser confirmado pela fala "quem está sozinho pode entrar numa diferente e nova roda de chimarrão".

\section{Rio Grande Record}

O programa tem duração de uma hora e é constituído por dois blocos, um de quinze minutos e outro de quarenta e cinco minutos. Possui apenas um apresentador, Farid Germano Filho, que está sempre em pé entre três televisões.

A vinheta de abertura (Figura 9), com o oferecimento do Banrisul, Colombo, Nacional, Nor Brasil e CR Diementz, é feita com um retângulo azul que diz "Rio Grande" e outro menor em vermelho que diz "Record". A abertura tem cerca de três segundos, e isso transfere para o telejornal acontecimentos rápidos e de grande eficiência. Assim, a luz que surge junto ao quadrado pode ser a representação de um flash em meio ao mapa do Rio Grande do Sul, que dá destaque ao nome do jornal.

Figura 9 - Vinheta de abertura do Rio Grande Record
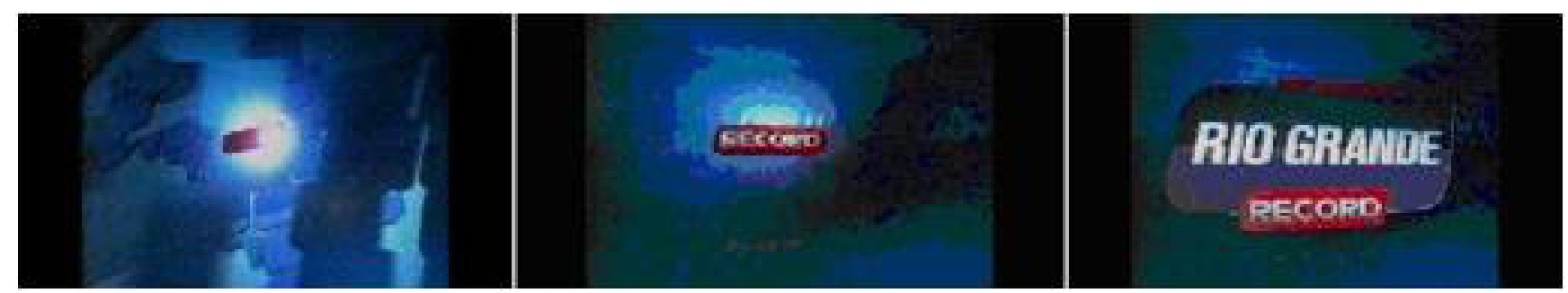
O jornal possui algumas autorreferenciações, como a chamada de outro jornal da própria emissora, com Sérgio Freitas e Ana Paula Padrão, o site R7, que estava na fase de lançamento, e por fim um merchandising da emissora dentro do próprio acampamento farroupilha, a "Casa da Record". Assim, tentam passar a ideia de que eles também são gaúchos, que também se incluem nessa tradição, provavelmente com o intuito de cativar o público.

A Semana Farroupilha foi mostrada no fim do último bloco. Os apresentadores falavam sobre "uma cidade dentro do parque", ou "pequena capital farrapa". Ainda, sobre os açougues, referiram-se a eles como "a menina dos olhos", aludindo à carne para feitura do churrasco.

\section{Considerações Finais}

A cultura regional é muito presente no estado do Rio Grande do Sul, e traços dessa cultura são apontados e atualizados na televisão e em outros meios de comunicação. Na televisão, que prioriza e compartilha essas características da cultura regional nos mais variados formatos de sua programação, isso é bem evidente.

Além das notícias da região, os telejornais apresentam peculiaridades marcantes explicitadas na fala e no cenário. De modo geral, pode-se dizer que eles denotam seriedade, o que é evidenciado nos cenários mais escuros, nos apresentadores sem muito movimento e nas roupas sem decotes. O tempo dos blocos varia muito, até mesmo de uma edição para outra. Entretanto, os intervalos são geralmente de dois minutos.

O Banrisul aparece como o maior patrocinador da Semana Farroupilha, isso possivelmente porque se identifica como o "banco dos gaúchos". Antes chamado de BRGS (Banco do Rio Grande do Sul), ele também afirma em seu slogan que "quem tem Banrisul tem tudo". Assim, podemos dizer que insinua que quem tem o banco dos gaúchos tem o que quiser, colocando o povo gaúcho em um "pedestal".

A Semana Farroupilha, ligada à tradição do Estado, mostra os principais costumes gaúchos, como a culinária, os acampamentos, as danças, as músicas, entre outros. Dessa forma, a identidade gaúcha é atualizada através de exemplos com as matérias da biblioparqk, da roda de chimarrão pela internet e tudo mais que é oferecido dentro do Acampamento Farroupilha para suprir necessidades, desde a infraestrutura às ritualísticas da tradição.

Os programas apresentados destacam a atualização e a transmissão de uma gauchidade que abastece todas as necessidades, até mesmo emocionais, com o intuito de impulsionar o consumo de bens simbólicos, buscando a caracterização e o apreço que os gaúchos sentem pelo Rio Grande, para que a "alma" farroupilha não morra. Para isso, utilizam cenários rústicos dentro do Acampamento, mostrando o gaúcho que come churrasco e carreteiro de charque, acorda e toma chimarrão, escuta músicas tradicionalistas e nativistas, fala da lida do campo, de um cotidiano rural vivenciado, via de regra, por uma minoria.

A televisão, em especial os telejornais, utilizam elementos constituidores de uma identidade do estado mais próxima da tradicionalista - gaúcho guerreiro e orgulhoso de sua tradição -, para ganhar audiência e se mostrar junto ao povo, numa tentativa de chamar pessoas de dentro e de fora do estado a se identificarem com esse gaúcho cada vez mais midiatizado e menos "rural".

\section{Referências}

BAUER, M. W.; GASKELL, G. Pesquisa qualitativa, com texto, imagem e som: um manual prático. 7. ed. Rio de Janeiro: Vozes, 2008.

CASETTI, F.; CHIO, F. Analisis de la televisión: instrumentos, métodos y prácticas de investigacion. Buenos Aires: Paidós, 1999.

DUARTE, Elizabeth Bastos; CASTRO, Maria Lília Dias (Orgs.). Televisão: entre o mercado e a academia. Porto Alegre: Sulina, 2009.

GILL, Rosalind. Análise do discurso. In: BAUER, M.W.; GASKELL, G. Pesquisa qualitativa com texto, imagem e som: um manual prático. 7.ed. Petrópolis: Vozes, 2008.

GOLIN, Tau. Identidades: questões sobre a representação sociocultural no gauchismo. Passo Fundo: Clio, Méritos, 2004.

HALL, Stuart. Quem precisa de identidade? In: HALL, Stuart; WOODWARD, Kathryn. Identidade e diferença: a perspectiva dos estudos culturais. Petrópolis: Vozes, 2000.

HINERASKY, Daniela A. O pampa virou cidade na TV: identidades nas séries histórias curtas. In: FELIPPI, Ângela.; NECCHI, Vitor. Mídia e identidade gaúcha. Santa Cruz do 
Sul: Edunisc, 2009. p. 147-170.

JACKS, Nilda. Querência: cultura regional como mediação simbólica, um estudo de recepção. Porto Alegre: UFRGS, 1999.

JOST, François. Seis lições sobre televisão. Porto Alegre: Sulina, 2004.

LISBOA FILHO, Flavi Ferraira. Mídia regional: gauchidade e formato televisual no Galpão Crioulo. 2009. 232f. Tese (Doutorado em Ciências da Comunicação) - Universidade do Vale do Rio dos Sinos. São Leopoldo, 2009.

- A gauchidade midiática televisual: enunciações de sentidos no Galpão Crioulo. In: FELIPPI, Ângela.; NECCHI, Vitor. Mídia e identidade gaúcha. Santa Cruz do Sul: Edunisc, 2009.

MACHADO, Arlindo. A televisão: levada a sério. 2. ed. São Paulo: EdSenac, 2001.

OLIVEN, Ruben George. A parte e o todo: a diversidade cultural no Brasil -nação. Petrópolis: Vozes, 2006.

ROSE, Diana. Análise de imagens em movimento. In: BAUER, M.W.; GASKELL, G. Pesquisa qualitativa com texto, imagem e som: um manual prático. 7.ed. Petrópolis: Vozes, 2008.

SOUZA, José Carlos Aronchi de. Gêneros e formatos na televisão brasileira. São Paulo: Summus, 2004.

WOODWARD, Kathryn. Identidade e diferença: uma introdução teórica e conceitual. In: HALL, Stuart; WOODWARD, Kathryn. Identidade e diferença: a perspectiva dos estudos culturais. Petrópolis: Vozes, 2000

Recebido para publicação: 01/05/2012 Aceito para publicação: 15/07/2012 